\title{
Effect of Load Shedding on Small Scale Entrepreneurs: A Case of Kitwe District of Zambia
}

\section{Banda Gerald ${ }^{\star x}$ Simukoko Garry ${ }^{2}$ Tailoka Frank Patson ${ }^{3}$}

${ }^{1,2}$ Mukuba University, Itimpi Campus, Kitwe, Zambia.

Email: gerald1banda@gmail.com

${ }^{s}$ Copperbelt University, School of Mathematics and Natural Sciences, Kitwe, Zambia.

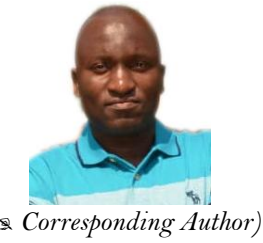

( Corresponding Author)

Abstract

Electricity is one of the key factors that are critical for accelerating the growth of the economy of the country. Without electricity, a number of sectors are affected. From 2014, Zambia has been facing serious load shedding which has an effect on the lives of people from academia to industry. The study was designed to determine the effect of load shedding on small scale entrepreneurs in Zambia. The approach for the study was mixed research. The sample for the study consisted of 200 people working in bars, salons, barbershops and in cafes. Simple random sampling was used to come up with 200 participants. Data for the study were collected through questionnaire and face to face interviews. Data for the study were analyzed using Analysis of Covariance. The null hypothesis was tested at $5 \%$ significance level. The findings of the study revealed that load shedding has negative effect on small scale entrepreneurs in Zambia.

Keywords: Load shedding, Small scale entrepreneurs, Electricity, Economy, Analysis of Covariance, Zambia.

Citation | Banda Gerald; Simukoko Garry; Tailoka Frank Patson (2020). Effect of Load Shedding on Small Scale Entrepreneurs: A Case of Kitwe District of Zambia. Economy, 7(2): 104-109. History:

Received: 11 September 2020

Revised: 5 October 2020

Accepted: 16 October 2020

Published: 29 October 2020

Licensed: This work is licensed under a Creative Commons

Attribution 3.0 License $(\mathrm{cc})$ E

Publisher: Asian Online Journal Publishing Group
Acknowledgement: Author greatly acknowledge the help from the lectures from Mukuba University who helped in validating of the instrument. Authors further thank all the participants from Ndeke Masuzyo market in Kitwe Zambia who took part in the study.

Funding: This study received no specific financial support

Competing Interests: The authors declare that they have no conflict of interests.

Transparency: The authors confirm that the manuscript is an honest, accurate, and transparent account of the study was reported; that no vital features of the study have been omitted; and that any discrepancies from the study as planned have been explained.

Ethical: This study follows all ethical practices during writing.

\section{Contents}

1. Introduction 105

2. Literature Review

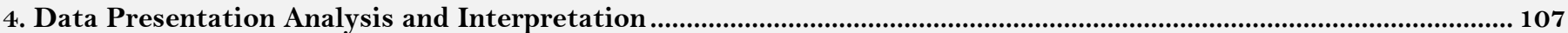

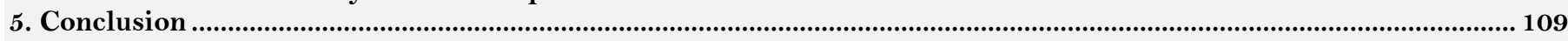

References 109 


\section{Contribution of this paper to the literature}

This study contributes to existing literature by determining the effect of load shedding on small scale entrepreneurs in Zambia.

\section{Introduction}

Zambia is a landlocked country situated in Southern-Central part of Africa. The major economic activities in Zambia are Mining, Agriculture, Tourism and Energy. Zambia has five large power stations. Four of the power stations are hydroelectric and one is thermal. Zambia has Ten Provinces and two provinces are dominated by mining activities. Copperbelt Province and North Western Province have been the backbone of Zambian economy as they produce minerals. The motivation for this study stems from the researchers' observation that load shedding has been and is still posing a number of challenges to citizens of Zambia. Since 2015, Zambia has been experiencing the worst electricity crisis. According to Zulu (2015) the major source of energy in Zambia is wood fuel (i.e. firewood and charcoal), with the largest consumer group being households in both rural and urban areas. According to Mwila (2017) the Electricity Supply Industry (ESI) in Zambia is dominated by hydro generation. According to Zulu (2015) hydro generation accounted for $96 \%$ of national installed capacity $2.1 \%$ is from alternative sources such as Diesel, Heavy Fuel Oil (HFO) and 1.7\% renewable comprising solar and small hydros. According to Mwila (2017) Zambia has experienced reduction in electricity supply which is as a result of the reduced generation by Zambia Electricity Supply Corporation (ZESCO) due to the low water levels in the reserves caused by poor rainfall. ZESCO was founded in 1970 and its headquarters is in Lusaka Zambia. ZESCO is a stateowned power company in Zambia. It is Zambia's largest power company producing about eighty percent of the electricity consumed in the country. These are the power stations under ZESCO: Kafue Gorge Upper produces 990 MW, Kariba North Bank produces 720 MW, Kariba North Bank Extension produces 360 MW, Victoria Falls produces $108 \mathrm{MW}$ and Itezhi-Tezhi Dam produces $120 \mathrm{MW}$. The power deficit since 2015 range from 560 to 1000 MW. Because of the power deficit, ZESCO increased the extent of load shedding to at least eight (8) hours a day for the majority of its household, commercial and industrial consumers. According to Phiri (2017) load shedding has negative effect on business growth and entrepreneurship. In most cases, load shedding affect business operations and financial viability; Small enterprises are the most likely to be adversely affected. Given the importance of electricity in Zambia especially small-scale entrepreneurs, it is important that the impact of load shedding is studied and understood. Therefore, the study investigated the impact of load shedding on small scale entrepreneurs.

\subsection{Statement of the Problem}

The key for economic growth for each and every country is the energy sector. Electricity is one of the key factors that are critical for accelerating the growth of the economy of the country. For example, the economy of Zambia has not been stable for the past five years. According to Economic Focus and Reports (2018) the Gross Domestic Product (GDP) per capita (USD) for Zambia in 2013 was 1,801 representing $5.1 \%$ of the Gross Domestic Product growth. In 2014, the Gross Domestic Product (GDP) per capita (USD) reduced from 1,801 to 1,661 representing 5\% of the Gross Domestic Product growth. In 2015, the Gross Domestic Product (GDP) per capita (USD) further reduced from 1,661 to 1,046 representing 2.3\% of the Gross Domestic Product growth. The 2016 Gross Domestic Product results shows an improvement in the economy. In 2016, the Gross Domestic Product (GDP) per capita (USD) increased from 1,046 to 1,293 representing 3\% of the Gross Domestic Product growth. In 2017, the Gross Domestic Product (GDP) per capita (USD) increased from 1,293 to 1,563 representing 4\% of the Gross Domestic Product growth. Gross Domestic Product per capita is a measure of a country's economic output that accounts for its people. Gross Domestic Product per capita is the best measurement of the country's standard living as it helps people to understand how prosperous a country feels to each of its citizen. It has been noted that a number of reasons could be attributed to the reduction of the Gross Domestic Product growth for the past five years and one of the reasons could be attributed to the continuous load shedding that the country has been experiencing from 2014. So, the study looked at the effect of load shedding on small scale entrepreneurs.

\subsection{The Purpose of the Study}

The purpose of the study was to investigate the effect of load shedding on small scale entrepreneurs with a special focus on Kitwe District on Copperbelt Province of Zambia. Small Scale entrepreneurs contribute a lot in the development of the economy of the country. If there is an interruption in the supply of electricity their business is disturbed. Salons, barbershops and other small-scale entrepreneurs depend on electricity for their businesses to run effectively. However, 2019-2020 load shedding has been worse. As a result of the power deficit, ZESCO increased the extent of load shedding in 2019-2020 to at least fifteen (15) hours a day for the majority of its household, commercial and industrial consumers. The study therefore aimed to establish to what extent small-scale entrepreneurs in Kitwe had been affected by electricity demand and ZESCO`s load shedding.

\subsection{Objectives}

In this study there are two objectives.

i. To find out the effect of load shedding on small scale entrepreneurs in Kitwe.

ii. To assess the measures taken by small-scale entrepreneurs if there is load shedding.

\subsection{Research Questions}

i. What are the effects of load shedding on small scale entrepreneurs in Kitwe?

ii. What are the measures in place if there is load shedding?

1.5. Hypothesis

$H_{0}: \tau_{1}=\tau_{2}=\tau_{3}=\tau_{4}=0$ (Load shedding has no effect on small scale entrepreneurs in Zambia). 


\section{$H_{1}$ : At least one of $\tau_{\text {is }}$ is different (Load shedding has an effect on small scale entrepreneurs in Zambia).}

\subsection{Significance of the Study}

This study will help in identifying the damage cause by load shedding on small scale entrepreneurs. Small scale entrepreneurs depend on electricity for their business to run smoothly. The findings of the study will be of great importance to policy makers on how they can help small-scale entrepreneurs.

\subsection{Limitation of the Study}

The study collected the opinions of small-scale entrepreneurs. Record keeping is a challenge for some smallscale entrepreneurs and some wanted to be paid money for them to disclose the information.

\section{Literature Review}

The main objective of conducting a literature review in this study is to analyse what other researchers had found concerning the effect of load shedding. The literature review is an important tool in research as it provides theoretical background to the study. According to Tichapondwa (2013) a literature review is an account of what has been published on a topic by accredited scholars and researchers. A number of studies have been conducted on the effect of load shedding and some of the studies are highlighted below.

The study that Mwila (2017) conducted shows that load shedding affects most business operations and financial viability. The study was conducted in Zambia and the aim of the study was to investigate the impact of load shedding on small scale enterprises. Findings of the study show that small enterprises were the most affected mainly due to their lack of resilience and limited capacity to invest in alternative energy sources. Most small enterprises resorted to reducing their work outputs resulting in reduced turnover whilst incurring additional costs such as idle labour and overtime. This study was conducted in Solwezi, North-Western Province while the current study was conducted in Kitwe District, Copperbelt Province. According to Phiri (2017) power rationing and load shedding has negative impact on both productivity and profitability. This study was conducted in Solwezi on the North-Western part of Zambia. The study looked at the impact of electricity demand and load shedding on Zambian business. A similar study was conducted in South Africa by Goldberg (2015). The findings of the study showed that load shedding has a negative effect on the retailers and on the economy of South Africa. Methodologies applied in the above studies are different from the current study.

Retail markets provide wide range of goods for public, reliable electricity supply is considered to be vital for the operations of retail businesses (Muhammad \& Nabi, 2017). The study was conducted in Hyderabad Pakistan and the title of the study is effects of load shedding on retail business: a glimpse from Hyderabad, Pakistan. Findings of the study show that problem in dealing customer and decrease in sales and waste of time were found to be the main factors that effect on business due to load shedding, while other factors like increase in cost, waste of time, product damage and health problems were also found to be effects of load shedding. The study is based on a quantitative survey using closed ended questionnaire. Sample consists of 262 was randomly selected from retail market of Hyderabad. Data was analyzed using SPSS 22.0 in terms of Bar Charts and multiple regression. The current study was conducted in Zambia and Analysis of Covariance was used to analyse the data. This was just the sample of the studies that have been conducted on the impact of load shedding.

\section{Methodology \\ 3.1. Research Design}

The purpose of the study is to investigate the impact of load shedding on small scale entrepreneurs in Zambia. According to Ranjit (2011) a research design is a procedural plan that is adopted by the researcher to answer questions validly, objectively, accurately and economically. According to Kothari (2004) a research design is the conceptual structure within which the research is conducted. Kothari (2004) further, explains that research design includes an outline of what the researcher will do from writing the hypothesis and its operational implications to the final analysis of data. In a simpler way, research design can be defined as a plan that helps a researcher to find out alternative tools to solve the problem. The study used mix methods approach in order to observe the impact of load shedding on small scale entrepreneurs in Zambian. Mixed research approach is the type of approach that involves collection of both open-ended and closed-ended data. According to Daniel (2004) mixed methods research, qualitative or quantitative components can predominate or both can have equal status. In this study, convergent parallel mixed approach was used. Qualitative data was gathered from the small-scale entrepreneurs about their views concerning load shedding whereas quantitative data was gathered from the statistics of the customers the small-scale entrepreneurs they have every day on average.

\subsection{Target Population}

The study was carried out on the Copperbelt Province of Zambia and Kitwe District in particular. Kitwe District was purposively chosen because of mine activities and load shedding in most cases is twelve to sixteen hours a day. The study investigated the effect of load shedding on small scale entrepreneurs. The target population of the study included all the people photocopying/printing, people selling beer in bars, people working in salons and people working in barbershops. According to Robert (2004) target population is the set of units to be studied.

\subsection{Sampling and Sampling Procedures}

The study used purposive sampling to come up with Kitwe District which is in Copperbelt Province of Zambia. According to Ranjit (2011) the primary consideration in purposive sampling is the judgement of the researcher as to who can provide the best information to achieve the objectives of the study. In purposive sampling the researcher only goes to those people who have the required information and are willing to share the information. Simple random sampling was also used when distributing questionnaires to 200 participants. 


\subsection{Data Collection Instrument}

In this study face-to-face interviews and questionnaires were used to collect data regarding the effect of load shedding on small scale entrepreneurs in Zambia. According to Nicholas (2011) face-to face interviews tend to concentrate in depth on a particular theme or topic with an element of interaction.

\subsection{Validity of Data Collection Instrument}

Validity of data collection instrument is an ability for the instrument to determining whether the findings are accurate from the standpoint of the researcher, the participant, or the readers (Creswell, 2014). The questionnaire was given to more than three lecturers. Corrections and suggestions made from the lecturers were used by the researchers to improve the questionnaire.

\subsection{Reliability of Data Collection Instrument}

The concept of reliability in relation to a research instrument means that a research tool is consistent and stable (Ranjit, 2011). According to Kothari (2004) reliability demonstrates that the operation of a study, such as the data collection procedures, can be repeated with the same outcome. The questionnaire on load shedding was developed by the researchers and was pre-tested through a pilot study to ascertain its reliability.

\section{Data Presentation Analysis and Interpretation}

This section presents analysis and interprets the data collected from the respondents by means of questionnaire.

\subsection{Data Presentation}

In this study Analysis of Covariance (ANCOVA) was applied.

\section{Model}

$y_{i j}=\mu+\tau_{i}+\beta\left(X_{i j}-\bar{X}_{i}\right)+\varepsilon_{i j}$

Where

$i=1,2,3,4$

$j=1,2,3,4$

- $y_{i j}$ is the $j^{\text {th }}$ observation under the $i^{\text {th }}$ treatment.

- $\mu$ is the grand mean.

- $\tau_{i}$ is the effect in the $i^{\text {th }}$ treatment.

- $\beta$ is the linear regression coefficient indicating the dependency of $y_{i j}$ on $x_{i j}$.

- $x_{i j}$ is the $j^{\text {th }}$ observation of the covariate under the $i^{\text {th }}$ group.

- $\bar{X}_{i}$ is the $i^{\text {th }}$ group mean.

- $\varepsilon_{i j}$ is the random error and $\varepsilon_{i j} \sim N\left(0, \sigma^{2}\right)$

For ANCOVA to be used the following assumptions should be met;

- Data should be drawn from the population by the means of random sampling.

- The relationship between the independent variable and the dependent variable must be linear.

- Independent variables must be drawn from the normal population.

- The regression coefficients in every group of the independent variable must be homogeneous.

Data on effect of load shedding on small scale entrepreneurs was collected and summarized in the table below;

Table-1. Number of Customers when there is load shedding and when there is no load shedding.

\begin{tabular}{|c|c|c|c|c|c|c|c|}
\hline \multicolumn{2}{|c|}{ Barbershop } & \multicolumn{2}{|c|}{ Salon } & \multicolumn{2}{|c|}{ Bar } & \multicolumn{2}{|c|}{ Photocopying/ Printing } \\
\hline$A$ & $B$ & $A$ & $B$ & $A$ & $B$ & $A$ & $B$ \\
\hline 5 & 10 & 3 & 10 & 20 & 25 & 15 & 20 \\
\hline 4 & 10 & 4 & 12 & 25 & 30 & 30 & 50 \\
\hline 7 & 20 & 3 & 8 & 28 & 40 & 60 & 100 \\
\hline 4 & 8 & 10 & 20 & 40 & 50 & 30 & 50 \\
\hline
\end{tabular}

A: No load shedding.

B: Load shedding .

Scores represents the number of customers per day.

$$
\begin{aligned}
& \operatorname{SST}_{A}=\sum_{i=1}^{K} \sum_{j=1}^{n} A_{i j}^{2}-\frac{A_{\ldots .}^{2}}{N} \\
& \operatorname{SST}_{A}=5^{2}+4^{2}+\cdots 30^{2}-\frac{(5+4+\cdots+30)^{2}}{16}=4090 \\
& \operatorname{SSTrt}_{A}=\sum_{i=1}^{k} \frac{A_{. i}^{2}}{n}-\frac{A_{\ldots}^{2}}{N} \\
& \operatorname{SSTrt}_{A}=\frac{20^{2}}{4}+\frac{20^{2}}{4}+\frac{113^{2}}{4}+\frac{135^{2}}{4}-\frac{(5+4+\cdots+30)^{2}}{16}=2764.5 \\
& \operatorname{SSE}_{A}=4090-2764.5=1325.5 \\
& \operatorname{SST}_{B}=\sum_{i=1}^{K} \sum_{j=1}^{n} B_{i j}^{2}-\frac{B_{\ldots}^{2}}{N}
\end{aligned}
$$




$$
\begin{aligned}
& \operatorname{SST}_{B}=10^{2}+10^{2}+\cdots 50^{2}-\frac{(10+10+\cdots+50)^{2}}{16}=8998.9375 \\
& \operatorname{SSTr}_{B}=\sum_{i=1}^{k} \frac{B_{. i}^{2}}{n}-\frac{B_{\ldots .}^{2}}{N} \\
& \operatorname{SSTrt}_{B}=\frac{48^{2}}{4}+\frac{50^{2}}{4}+\frac{145^{2}}{4}+\frac{220^{2}}{4}-\frac{(5+4+\cdots+30)^{2}}{16}=5159.1875 \\
& \operatorname{SSE}_{B}=8998.9375-5159.1875=3839.75 \\
& \operatorname{SST}_{A B}=\sum_{i=1}^{K} \sum_{j=1}^{n_{i}}\left(A_{i j}\right)\left(B_{i j}\right)-\frac{\left(A_{\ldots}\right)\left(B_{\ldots}\right)}{N} \\
& \operatorname{SST}_{A B}=5(10)+4(10)+\cdots+30(50)-\frac{288(463)}{16}=5900 \\
& \operatorname{SSTrt}_{A B}=\sum_{i=1}^{k} \frac{\left(A_{. i}\right)\left(B_{. j}\right)}{n_{j}}-\frac{\left(A_{\ldots}\right)(B \ldots)}{N} \\
& \operatorname{SSTrt}_{A B}=\frac{106(664)}{4}+\frac{134(708)}{4}+\frac{3409(5625)}{4}-\frac{5625(15400)}{16}=3677.25 \\
& \operatorname{SSE}_{A B}=5900-3677.25=2222.75 \\
& (\mathrm{a}) \operatorname{SST}_{(a d j)}=S S T_{A}-\frac{\left(S S T_{A B}\right)^{2}}{S S T_{B}}
\end{aligned}
$$$$
S S T_{(a d j)}=4090-\frac{(5900)^{2}}{8998.9375}=221.77
$$$$
S S E_{(a d j)}=S S E_{A}-\frac{\left(S S E_{A B}\right)^{2}}{S S E_{B}}
$$$$
S S E_{(a d j)}=1325.5-\frac{(2222.75)^{2}}{3839.75}=38.8
$$$$
S S T r t_{(a d j)}=S S T_{(a d j)}-S S E_{(a d j)}
$$$$
\operatorname{SSTrt}_{(\text {adj })}=221.77-38.8=182.97
$$

$\mathrm{Or}$

$$
\begin{aligned}
& \operatorname{SSTrt}_{(a d j)}=S S T_{A}-S S E_{A}+\frac{\left(S S E_{A B}\right)^{2}}{S S E_{B}}-\frac{\left(S S T_{A B}\right)^{2}}{S S T_{B}} \\
& \operatorname{SSTrt}_{(a d j)}=4090-1325.5+\frac{(2222.75)^{2}}{3839.75}-\frac{(5900)^{2}}{8998.9375}=182.97
\end{aligned}
$$

\begin{tabular}{l|c|c|c|c}
\multirow{2}{*}{ ANCOVA Table } & \multicolumn{1}{l}{ Table-2. Descriptive statistics on effect of load shedding. } \\
\cline { 1 - 3 } Source & $\boldsymbol{S S}$ & $\boldsymbol{d} \boldsymbol{f}$ & $\boldsymbol{M S}$ & $\boldsymbol{F}^{*}$ \\
\hline Treatment & 182.97 & 3 & 60.99 & 17.29 \\
\cline { 1 - 2 } Error & 38.8 & 11 & 3.527 & \\
\hline Total & 221.77 & 14 & & \\
\hline
\end{tabular}

\subsection{Decision Rule}

Reject $H_{0}$ if $F^{*}>f_{3,11}^{\alpha=0.05}=3.5874$

\subsection{Conclusion}

Since $F^{*}=17.29>f_{3,11}^{\alpha=0.05}=3.5874$, we reject $H_{0}$ at $5 \%$ level of significance and conclude that load shedding has effect on small scale entrepreneurs.

\subsection{Discussion}

From the calculations above, where $F^{*}=17.29>f_{3,11}^{\alpha=0.05}=3.5874$, we reject $H_{0}$ at $5 \%$ level of significance and conclude that load shedding has effect on small scale entrepreneurs. The findings in this study are in line with the study conducted by Mwila (2017). The study that Mwila (2017) conducted shows that load shedding affects most business operations and financial viability. The information from this study revealed that the majority of people agree that load shedding is a bad thing to people. There is need for the government of Zambia to find lasting solution for load shedding. For instance, most of the people selling beer in bars have minimum of 50 customers a day if there is no load shedding. In 2019 load shedding was cutting for a minimum of twelve hours a day. If there is load shedding for example, power cuts at 1800 hours, many customers can not be buying beer in darkness and most of the customers drink beer after 1800 hours. Bar owners are spending extra money buying generators to keep the business moving. Most people interviewed who sells beer reviewed that if there is load shedding the number of customers reduced. The reduction in customers has a negative effect on the business and the income reduces. The information gathered from people working in cafes revealed that load shedding destroys their business. Some have lost printing and photocopying machines because of load shedding. Some machines were burnt because of load shedding and in most cases if there is load shedding, they end up not having customers. The 2019 load shedding was bad for business of printing and photocopying because of the number of hours power was taking to be restored. Some people who were interviewed complained bitterly about load shedding and said that load shedding has made their lives difficult because they can't support their families adequately financially. 
Barbershops and salons have been affected negatively by load shedding. Not only barbershops and salons, but council workers are also a victim of load shedding. Some people working in barbershops and salons pay rentals to Kitwe City Council. Because of load shedding most of them fail to pay rentals to Kitwe City Council and Kitwe City Council workers sometimes go months without being paid their monthly salary. School fees for the children whose parents work in barbershops and solons was difficult to pay because their parents cannot raise enough money to feed children at home and pay school fees for their children. Some markets in Kitwe District have one prepaid meter for electricity to supply to all the shops in the market. If power cut at 1800 hours, people who benefits are those working in bars selling beer because with them they can work until midnight. As a result, some people buy electricity units without benefiting from them. A number of people interviewed complained about load shedding as they cannot afford to buy generators. Reliable electricity supply is considered to be vital for the operations of business for small-scale entrepreneurs. This is in support of the study conducted by Muhammad and Nabi (2017). If there is load shedding business is disturbed and the income generation is reduced. To avoid making loses, people have resorted to be using generators if there is load shedding.

\section{Conclusion}

Small-scale entrepreneurs play an important role in the development of the country as they pay tax to the government. An increase in load shedding reduces revenue small-scale entrepreneurs generate every month. Results showed that load shedding has negative effect on small scale entrepreneurs in Zambia. Based on the statistical calculations using Analysis of Covariance and a number of people who were interviewed, load shedding has negatively impacted small scale entrepreneurs and a number of families have been suffering financially. Therefore, the study found that load shedding affects the economy in Zambia negatively and people should find other sources of power rather than depending of ZESCO. It is important for both the government and public to take corrective actions because all are ultimate beneficiaries.

\section{References}

Creswell, J. W. (2014). Research design: Qualitative, quantitative and mixed methods approaches (4th ed.). California: SAGE.

Daniel, M. (2004). Doing quantitative research in education with SPSS. London: SAGE Publications Ltd.

Economic Focus and Reports. (2018). Zambian economic outlook. Lusaka Zambia: Economic Focus and Reports.

Goldberg, A. (2015). The economic impact of load shedding: The case of South African retailers. Pretoria: Gordon Institute of Business Science. University of Pretoria.

Kothari, C. R. (2004). Research methodology: Methods and techniques (2nd ed.). Jaipur: New Age.

Muhammad, N., \& Nabi, N. B. (2017). Effects of loadshedding on retail business: A glimpse from Hyderabad, Pakistan. Grassroots, 51(1), 166177.

Mwila, A. (2017). Impact of load shedding on small scale enterprises. Lusaka: Energy Regulation Board.

Nicholas, W. (2011). Research metheds. The basics. London: Routledge.

Phiri, J. (2017). Electricity demand and loadshedding: Impact on Zambian business: A case study of selected solwezi based businesses. International Journal of Multidisciplinary Research and Development, 146-157.

Ranjit, K. (2011). Research methodology: A step-by-step guide for beginners. New Delhi: SAGE.

Robert, C. M. (2004). Survey methodology. New Jersey: A John Wiley \& Sons, Inc.

Tichapondwa, S. (2013). Preparing your dissertation at a distance: A research guide. Vancouver: Virtual University.

Zulu, H. (2015). Energy Statistics in Zambia. Lusaka: Department of Energy. 